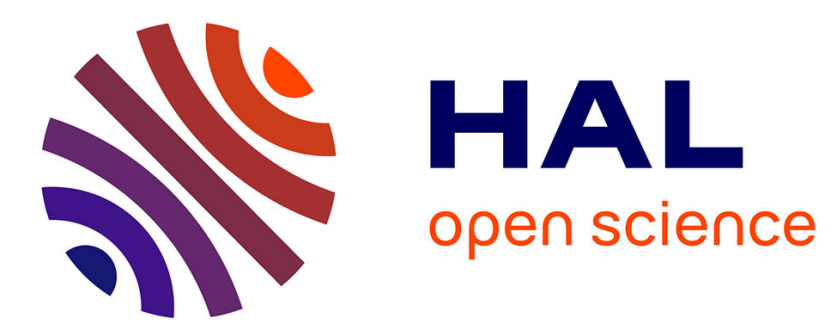

\title{
STUDY ON N2/CO2 MIXING GASDYNAMIC LASER BY MEANS OF SYNCHRONIZED OPERATION OF TWO SHOCK TUBES
}

K. Maeno, H. Oguchi

\section{- To cite this version:}

K. Maeno, H. Oguchi. STUDY ON N2/CO2 MIXING GASDYNAMIC LASER BY MEANS OF SYNCHRONIZED OPERATION OF TWO SHOCK TUBES. Journal de Physique Colloques, 1980, 41 (C9), pp.C9-209-C9-215. 10.1051/jphyscol:1980927 . jpa-00220581

HAL Id: jpa-00220581

https://hal.science/jpa-00220581

Submitted on 1 Jan 1980

HAL is a multi-disciplinary open access archive for the deposit and dissemination of scientific research documents, whether they are published or not. The documents may come from teaching and research institutions in France or abroad, or from public or private research centers.
L'archive ouverte pluridisciplinaire HAL, est destinée au dépôt et à la diffusion de documents scientifiques de niveau recherche, publiés ou non, émanant des établissements d'enseignement et de recherche français ou étrangers, des laboratoires publics ou privés. 
STUDY ON $\mathrm{N}_{2} / \mathrm{CO}_{2}$ MIXING GASDYNAMIC LASER BY MEANS OF SYNCHRONIZED OPERATION OF TWO SHOCK TUBES

K. Maeno and H. Oguchi ${ }^{*}$

*okyo Metropolitan College of Aeronautical Engineering, Tokyo, Japan.

* Institute of Space and Aeronautical Science, University of Tokyo, Tokyo, Japan.

\begin{abstract}
Rêsumé.- On expérimente l'obtention de GDL par mélange de $\mathrm{N}_{2}$ et de $\mathrm{CO}_{2}$ à 1'aide d'un bec à écran conçu pour un mélange supersonique aval, par utilisation synchronisée de ${ }^{2}$ deux tubes de choc séparés. Les distributions de gain mesurées sont comparées à une estimation fondée sur une analyse simplifiée quasi uni-dimensionnelle.

Abstract. - The experiment on $\mathrm{N}_{2} / \mathrm{CO}$ mixing GDL is conducted using a screen nozzle, contrived to make supersonic downstream mixing, ${ }^{2}$ by means of a synchronized operation of two separate shock tubes. The measured gain distributions are compared with an estimate based on simplified, quasi one-dimensional analysis.
\end{abstract}

\section{Introduction}

In this paper we concern a $\mathrm{N}_{2} / \mathrm{CO}_{2}$ mixing $\mathrm{GDL}$ experiment. It has already been demonstrated by previous investigators $1-11$ that a mixing GDL is one of the promising and powerful methods transcending a gain limit pertinent to a conventional premixed GDL; notably, comprehensive reviews should be referred to Refs. 9 and 11 . So far as thermal excitation of the donor gas $\mathrm{N}_{2}$ is concerned, the shock tube is one of the most useful means, because of the feasibility to cover a wide range of flow conditions.

Regarding the mixing of $\mathrm{CO}_{2}(+\mathrm{He})$ with a donor gas $\mathrm{N}_{2}$, various schemes for the injection of $\mathrm{CO}_{2}$ into a supersonic nozzle of $\mathrm{N}_{2}$ have been noticed and/or. contrived; for example, a normal throat injection from wall or slotted tube vertically mounted at the nozzle throat, ${ }^{3,4}$ a downstream screen nozzle injection with sonic nozzle of $\mathrm{CO}_{2},{ }^{5}$ and further a supersonic downstream injection by screen nozzle. ${ }^{6}$ In any scheme, however, the gasdynamics pertinent to mixing processes above mentioned is so intricate that simplified assumptions could be involved in any analysis; otherwise, the descrip- tion of the relevant flow phenomena must largely rely on the experimental evidences.

As a mixing scheme of our experiment is chosen a screen nozzle which proved to yield high gain. This screen nozzle enabled us to make a supersonic downstream mixing of a donor gas with $\mathrm{CO}_{2}$ with or without catalyst He. The screen nozzle is rather fixed in configuration and designed to comprise of simple conical nozzles, because optimization of the nozzle configuration is not our primary purpose. This paper aimes to clarify some of fundamental characteristics of $\mathrm{N}_{2} / \mathrm{CO}_{2}$ mixing $\mathrm{GDL}$, associated with supersonic downstream mixing over a wide range of stagnation conditions of the component gases.

\section{Experimental Apparatus}

This experiment was conducted by a synchronized operation of two shock tubes, which produce separate stagnant conditions for each gas. These two tubes have quite the same driving mechanism, which is illustrated in Fig. 1. The diaphragm of an ordinary shock tube is replaced by a free piston which is contrived to quickly move back and forth 
following the movement of an auxiliary free piston. The auxiliary piston can be moved by on-off switching of small magnetic valve, equipped outside of the compression chambers. Consequently, the operation of each tube can be made simply by a snap action. Both feasibility and reproducibility of the operation is quite satisfactory, as previously reported in Refs 12, 13. Thus, the synchronized operation of these two tubes was easily achieved by electric control of the respective magnetic valves.

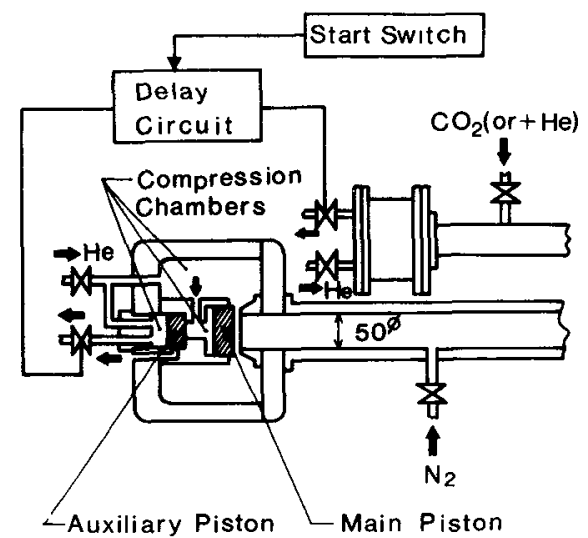

Fig. 1 Schematic diagram of driver sections.

The shock tubes are different from each other in dimension; the tube for a donor gas $\mathrm{N}_{2}$ has a driven section of $50 \mathrm{~mm}$ in inner diam. and $5,500 \mathrm{~mm}$ in length with the following $20 \times 80 \mathrm{~mm}$ square cross section, and the other for $\mathrm{CO}_{2}$ has a driven section of $20 \mathrm{~mm}$ in inner diam. and 5,000 $\mathrm{mm}$ in length.

The terminal section of the $\mathrm{CO}_{2}$ tube is connected with the screen nozzle through a straight tube, and initially separated by insertion of a polyethylen diaphragm, thin enough to break at arrival of the shock wave, in a port of the connection tube (Fig. 2).

The screen nozzle is installed within the square cross section $(20 \times 80 \mathrm{~mm})$ and the laser cavity is followed with the same cross section downstream of the nozzle exit. The windows for optical observation as well as gain measurement are mounted flush with the side walls of the cavity. In Fig. 3 is

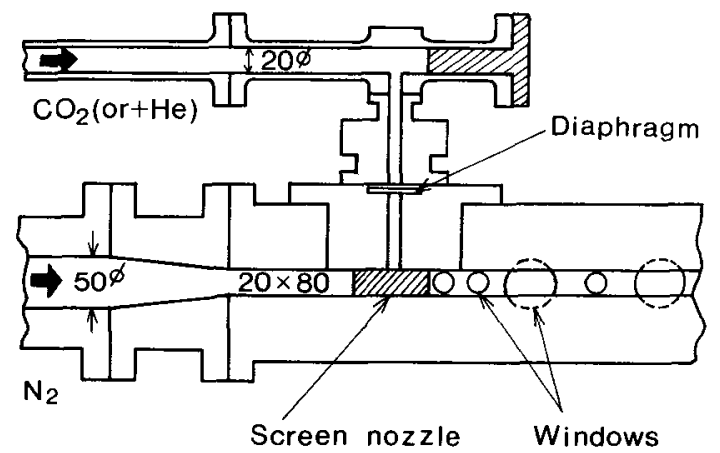

Fig. 2. Test section.

shown the schematics of the screen nozzle. Since, in the experiment, the optimization of the nozzle configuration was not aimed, a simple geometry which consists of conical supersonic nozzles was chosen; that is, one row of 6 nozzles for $\mathrm{CO}_{2}$ sandwiched with two rows of 8 nozzles for $\mathrm{N}_{2}$. No separation diaphragm was used, because of the small area ratio of throat to cross section $5 \%$; this assured further feasibility of the operation, though a slight loss in flow duration was incurred.
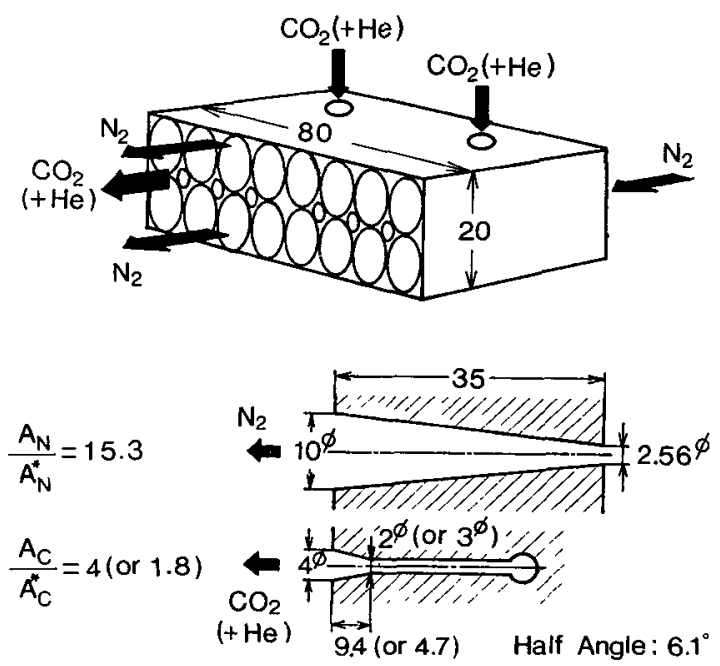

Fig. 3. Screen nozzle.

Operation and Experimental Conditions

The driver gas was helium, which was charged from 6 up to $20 \mathrm{~atm}$ for the tube of a donor gas $N_{2}$ and from 5 to $10 \mathrm{~atm}$ for the tube of $\mathrm{CO}_{2}$. Regarding driven pressure, a donor gas $\mathrm{N}_{2}$ was filled at 
a pressure from 20 to 50 Torr, while the $\mathrm{CO}_{2}$ was filled at a pressure from 200 to 400 Torr.

The pressure was measured by means of piezoelectric pressure gauges mounted at appropriate locations close to the end wall (or the front face of screen nozzle). The incident shock speed was recorded on the time counters detecting shock arrival by pressure gauges. In Fig. 4 is shown an example of pressure records, either of which is that for a donor gas just ahead of the front face of screen nozzle or that for $\mathrm{CO}_{2}$ just ahead of the end wall. We can see from this figure that a satisfactory synchronization of two shock tubes is achieved. In fact, the operation was capable of making the difference in arrival times of both incident shock waves less than about $2 \sim 3 \times 10^{2} \mu \mathrm{sec}$. Since the flow duration estimated from the pressure history were about $2 \mathrm{msec}$ for a donor gas $\mathrm{N}_{2}$ and about $4 \mathrm{msec}$ for $\mathrm{CO}_{2}$, the achieved synchronization was tolerable for the measurement of any lasing performance. Apparently, this must be further improved if longer driven tubes are available to use.

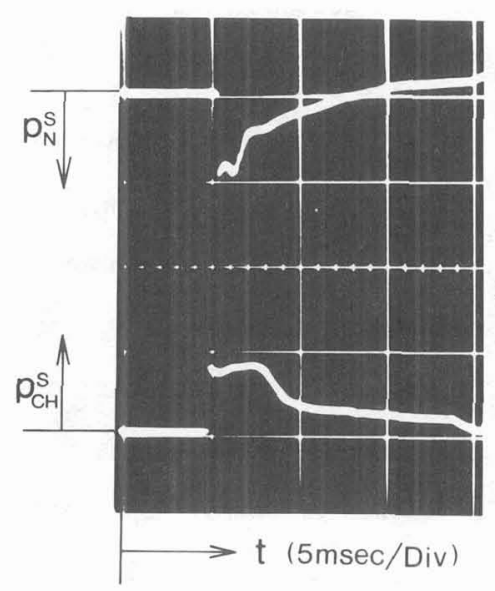

Fig. 4. Pressure record at shock tube ends.

The stagnation temperatures were estimated from the ideal reflected shock relation using the measured incident shock speeds. The experimental conditions regarding the stagnation pressure and temperature are summarized as follows:

$$
\begin{aligned}
& 2 \mathrm{~atm}<\mathrm{p}_{\mathrm{C}}^{\mathrm{S}}<6 \mathrm{~atm}, \quad 500^{\circ} \mathrm{K}<\mathrm{TS}_{\mathrm{C}}^{\mathrm{S}}<2400^{\circ} \mathrm{K} \\
& 2 \mathrm{~atm}<\mathrm{p}_{\mathrm{CH}}^{\mathrm{S}}<5 \mathrm{~atm}, \quad 700^{\circ} \mathrm{K}<\mathrm{T}_{\mathrm{CH}}^{\mathrm{S}}<2300^{\circ} \mathrm{K} \\
& 5 \mathrm{~atm}<\mathrm{p}_{\mathrm{N}}^{\mathrm{S}}<10 \mathrm{~atm}, 1800^{\circ} \mathrm{K}<\mathrm{T}_{\mathrm{N}}^{\mathrm{S}}<3500^{\circ} \mathrm{K}
\end{aligned}
$$
where $p^{S}$ and $T^{S}$ are pressure and temperature at stagnation, respectively, and the subscripts $\mathrm{N}, \mathrm{C}$, and $\mathrm{CH}$ refer to the test gases $\mathrm{N}_{2}, \mathrm{CO}_{2}$, and mixture of $\mathrm{CO}_{2} / \mathrm{He}$, respectively. It is noted that no dissociation occurs for either $\mathrm{CO}_{2}$ or $\mathrm{N}_{2}$ over this experimental condition.

\section{Measurement of Small Signal Gain Coefficient}

The small signal gain $G$ was determined from the intensity increment of the beam which was produced by an electrically pumped $\mathrm{CW} \mathrm{CO}_{2}$ laser. The beam homogeneously scattered by reflection upon a diffusive alminium mirror was set to pass through Ge windows, so that the beam intensity was measured by a dewer-type $\mathrm{Hg}$-Cd-Te photoconductive infrared detector. The measurement scheme for small signal gain is illustrated in Fig. 5. Care was

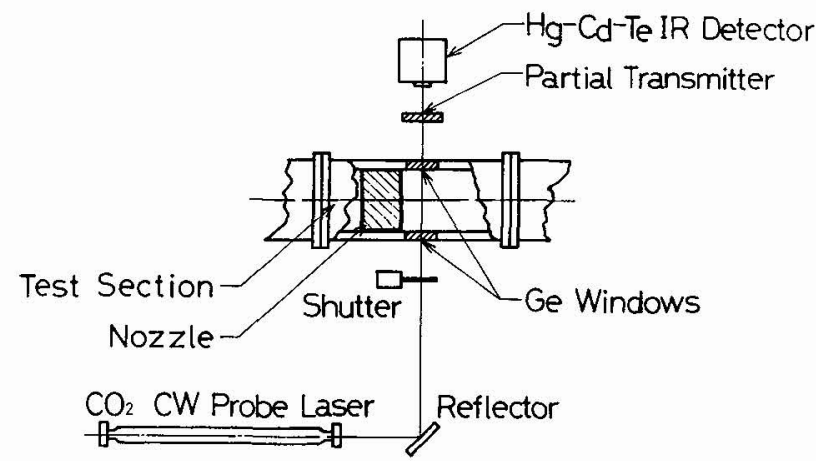

Fig. 5. Arrangement of gain measurement. taken for protection of the $\mathrm{Hg}-\mathrm{Cd}-\mathrm{Te}$ infrared detector; for example, a shutter was inserted in a beam path to avoid unnecessary exposer of the detector to the continuous beam, and also a Ge transmitter was inserted in front of the detector in order to attenuate the beam intensity.

Since the test time was comparatively short, 
the beam intensity prior to the flow start or nonarrival of the lasing media indicated no appreciable change during the test time. Therefore, this initial intensity was able to regard as the undisturbed beam intensity $I_{0}$. In Fig. 6 an example of the beam signal is shown together with the pressure history at the end of the $\mathrm{CO}_{2}$ tube. The flow in a cavity is estimated to start after at most a few hundreds microseconds from arrival of the incident shock wave at the end of the $\mathrm{CO}_{2}$ tube (the initial rise of the pressure in Fig. 6). It is noted that the maximum of gain is achieved with some delay from the flow start. This was also confirmed not to be caused by mismatch in operation of the two tubes. The gain distributions along the center axis as well as lines normal to the axis were measured at window locations downstream of the nozzle exit.

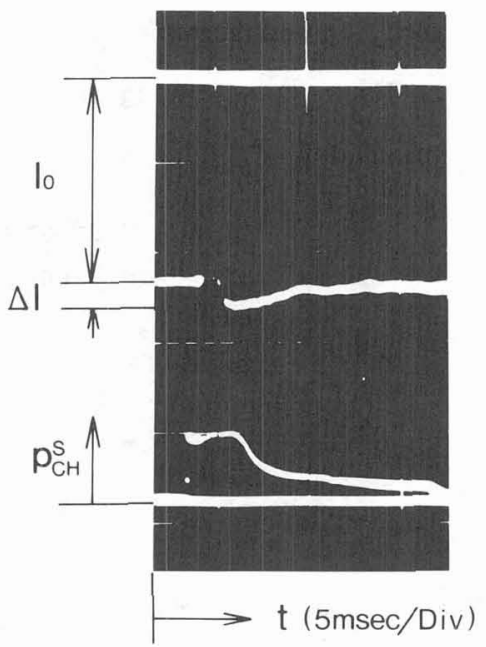

Fig. 6. Gain signal and pressure of $\mathrm{CO}_{2}$ tube.

Simple Estimate by Quasi One-Dimensional Analysis

- for Comparison with Experiment -

So far there have been worked out many investigations on the screen nozzle of a single gas from a viewpoint of the application to wind tunnel or other fluid machinery. Recently, for gasdynamic laser application Russel et al ${ }^{14}$ developed an ela- borate analysis of the screen nozzle flow, taking into account of the viscous effects. Cassady et a ${ }^{11}$ extensively applied it to an estimate of the laser performance for the mixing GDL using a screen nozzle similar to the present one, and showed a reasonable agreement of the estimate with their experiment. Even in these elaborate analyses, the flow behavior in the mixing region is not dealt with. This is mainly because the mixing processes of viscous flows mismatched in velocity and temperature are much intricate for the straightforward analysis. ${ }^{15}$ In addition, the outgoing disturbances from the nozzle exit are also untractable without any semi-empirical considerations.

Regarding the mixing GDL flow analysis, more simple analysis was done by Soloukhin et al ${ }^{9}$ for the mixing nozzle scheme, in which the secondary sonic jet is injected at the throat or from the side wall of a primary nozzle flow of a donor gas. In their analysis, one of the most simplifing assumptions is that of an instataneous mixing. Despite such a simple analysis, the estimate was shown to be in a reasonable agreement with their own experiment.

In this paper, for the present mixing GDL flow we performed a simple analysis of flows, which provides an estimate of the lasing performance or small signal gain. As in Reference 9, the analysis is based on the assumption of the quasi one-dimensionality, instantaneous mixing at the nozzle exit and negligible viscous effects. Apparently, the above assumptions reduce the analysis to a great deal of simplification. Regarding a chemical kinetics involved, the vibrational energy relaxation processes are followed by the three-mode model, in which each mode is in local equilibrium as harmonic oscillator, and chemical equilibrium establishes at each throat of the screen nozzle. 
Once the stagnation condition of each component gas $\mathrm{N}_{2}$ or $\mathrm{CO}_{2}(+\mathrm{He})$ and the geometry of nozzles are prescribed, a set of governing equations can be integrated from the throat to the exit, separately for each nozzle. Since the instantaneous mixing just at the nozzle exit is assumed, the flow properties at the nozzle exit after mixing are determined from the algebraic conservation equations, in which all the vibrational temperatures pertinent to each mode are assumed to remain unchanged across the mixing layer. With the flow properties after mixing, thus obtained at the exit, the governing equations are also integrated through the cavity from the exit toward downstream. The estimate of small signal gain obtained by the above analysis will be compared with the present experiment.

Results and Discussion

In Fig. 7 is shown the distribution of small signal gain coefficient $G(1 / m)$, measured at several locations along the center axis from the nozzle exit toward downstream. Two kinds of measurement data are plotted for a fixed stagnation condition of a donor gas $\mathrm{N}_{2}$; namely, one is for the case of mixing with pure $\mathrm{CO}_{2}$ and the other for the case of mixing with a mixture $\mathrm{CO}_{2} / \mathrm{He}$. For comparison, the estimates, obtained by the simple analysis in the previous section, are also plotted in the same

figure. It follows from the figure that the effect of catalyst $\mathrm{He}$ is not so appreciable on an achieved maximum gain but the decrease in gain toward downstream is suppressed by addition of the catalyst. Further, for cases of a mixture $\mathrm{CO}_{2} / \mathrm{He}$, the simple estimate of $G$ is rather lower than the measured data. This is likely to be mainly due to the fact that, as shown later, the gain $G$ on the axis takes the maximum in the distribution along a line normal to the axis. It also follows from the figure that

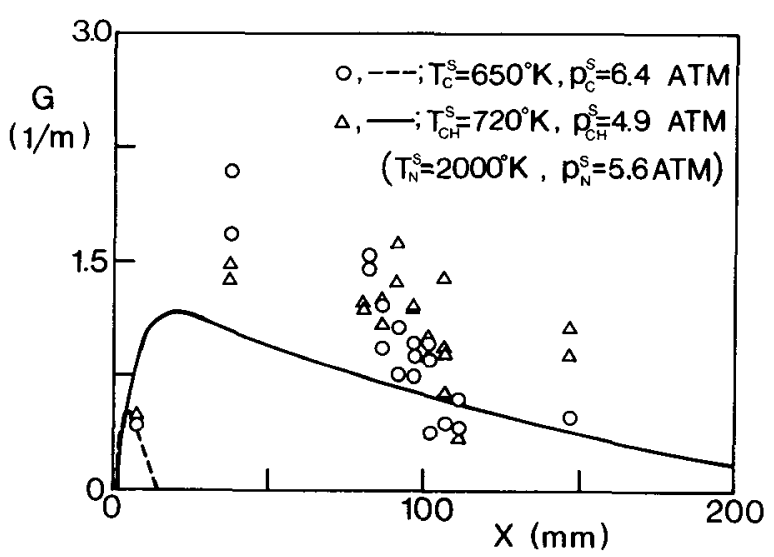

Fig. 7. Gain distribution along center of cavity. the gain distribution of a qualitative behavior is reasonably similar to that from the simple analysis.

For the case of pure $\mathrm{CO}_{2}$, however there appears a great discrepancy of the estimate from the data. As previously mentioned, the present estimate is based upon the neglection of loss due to the viscosity as well as disturbances, along with an ideal mixing. Therefore, the estimate thus obtained must lead an overestimate of the gain. Nevertheless, for the case of pure $\mathrm{CO}_{2}$, the data indicate the gain much greater than the estimate. Physical explanation on this discrepancy must remain in future study.

The gain distributions over lines normal to the axis were measured at several stations from the nozzle exit toward downstream. The data are shown in Fig. 8, where $x$ is measured along the nozzle exit toward downstream and $y$ normal to it. As ex-
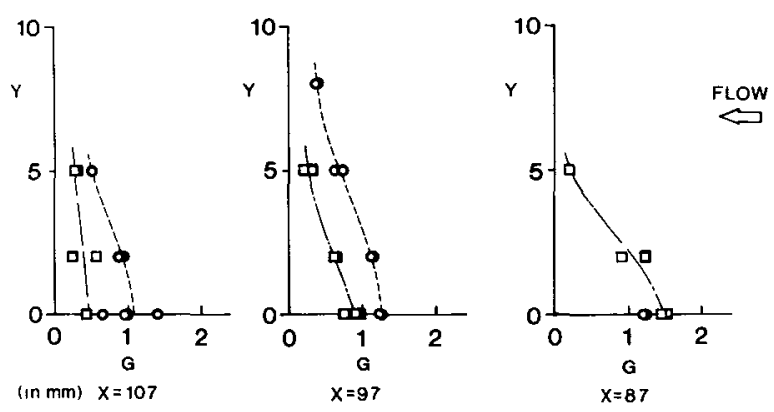

Fig. 8. Gain distributions normal to flow. $\mathrm{O}: \mathrm{CO}_{2} / \mathrm{He}, \mathrm{a}$ : pure $\mathrm{CO}_{2}$. 
pected, the maximum gains occur on the axis $y=0$ and a steeper profile at the station closer to the nozzle exit becomes plateau toward downstream. The experimental condition for the data shown in Fig. 8 was the same as that shown in Fig. 7. In these measurements, the area ratio of $\mathrm{CO}_{2}$ nozzle was 1.8 with the throat of $3 \mathrm{~mm}$ in diam. (see Fig. 3), so that the mole fraction of $\mathrm{CO}_{2}$ was comparatively larger; equivalent mole fraction was $56 \mathrm{~N}_{2} / 44 \mathrm{CO}_{2}$ or $53 \mathrm{~N}_{2} / 79 \mathrm{CO}_{2} / 28 \mathrm{He}$, respectively, for pure $\mathrm{CO}_{2}$ or $\mathrm{CO}_{2} /$ He injection.

In order to elucidate the effect of the stagnation conditions on the achieved gain, the gain measurement was conducted at a fixed reference station which is located on the center axis of 97 $\mathrm{mm}$ downstream from the nozzle exit, in variation of $\mathrm{N}_{2}$ stagnation condition for a fixed $\mathrm{CO}_{2} / \mathrm{He}$ stagnation condition, and vice versa. The results are summarized in Figs. 9 and 10, together with the estimate obtained by the simple analysis previously mentioned. A stagnation condition is specified by a set of temperature and pressure. In variation of stagnation condition of $\mathrm{N}_{2}$ (or $\mathrm{CO}_{2}$ ), not only temperature but pressure varied, so that the equivalent mole fraction after the mixing also varied. Thus the equivalent mole fraction $\Psi_{N}$ of $N_{2}$ is plotted vs the stagnation temperature $\mathrm{T}^{\mathrm{s}}$. The optimum gain appears to depend sensitively on the $\mathrm{CO}_{2} / \mathrm{He}$ stagnation condition than on the $N_{2}$ stagnation condition, except higher temperature region $\left(T_{N}^{S}>2.5\right.$ $\left.\times 10^{3}, \mathrm{~T}_{\mathrm{CH}}^{\mathrm{S}}>1.5 \times 10^{3}\right)$. It can also be seen that the present estimate provides a good agreement with the experiment.

Finally, in this experiment an advantage of this type of mixing GDL was confirmed in comparison with a conventional premixed GDL, though the geometry of the nozzle was not necessarily an optimized one. The simple estimate based on the assump- tions of quasi one-dimensionality, instantaneous mixing, and neglection of viscosity as well as disturbances is shown to simulate at least qualitative behavior of small signal gain, so far as the catalyst $\mathrm{He}$ is contained in lasing media $\mathrm{CO}_{2}$. For cases of no catalyst, however there appears a great discrepancy of the simple estimate from the data. Physical explanation on this discrepancy remains in future study.

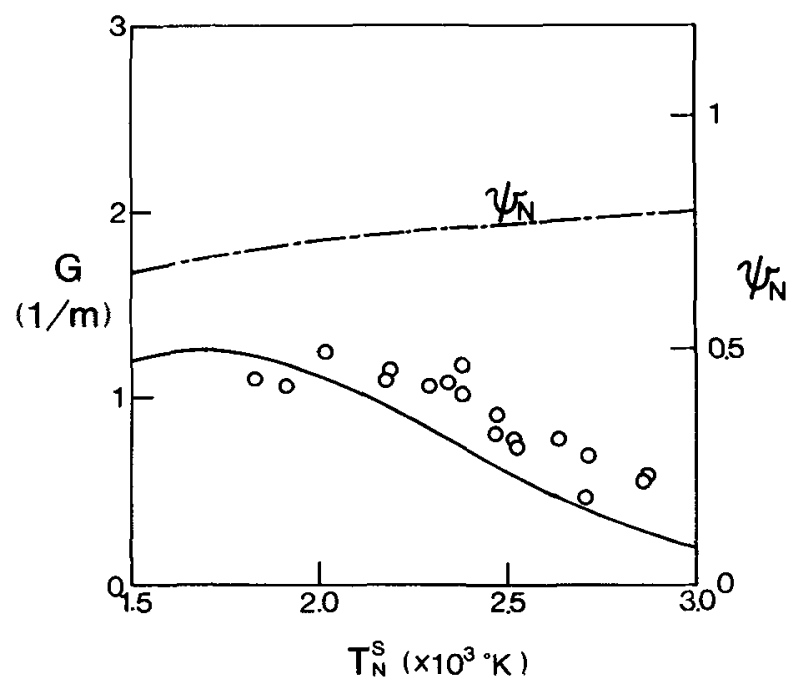

Fig. 9. Effect of $\mathrm{N}_{2}$ stagnation condition on gain for fixed $\mathrm{CO}_{2}$ stagnation; $\mathrm{T}_{\mathrm{CH}}^{\mathrm{S}}=720^{\circ} \mathrm{K}$, $\mathrm{p}_{\mathrm{CH}}^{\mathrm{S}}=4.8 \mathrm{~atm}, \quad \mathrm{CO}_{2}: \mathrm{He}=2: 3, \mathrm{~A}_{\mathrm{C}} / \mathrm{A}_{\mathrm{C}}=4$.

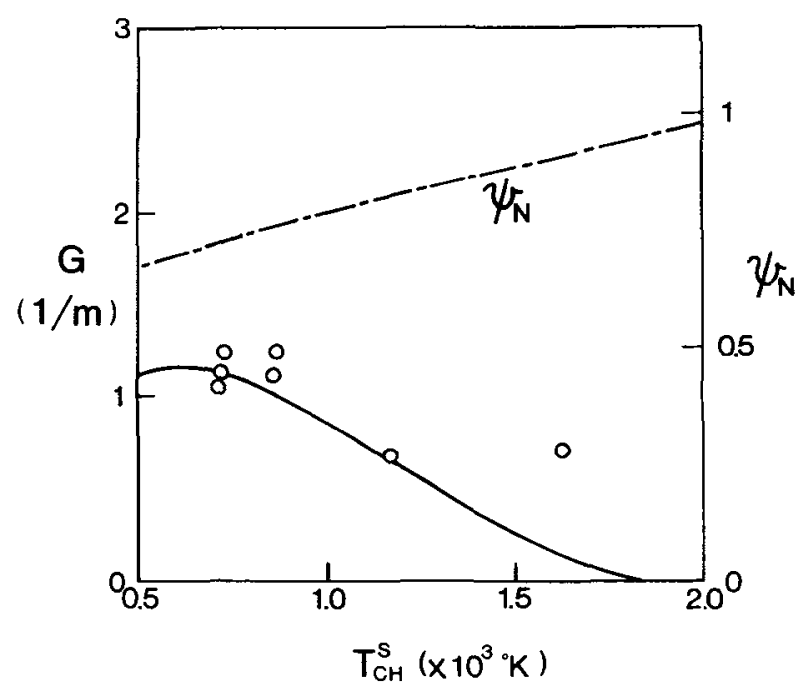

Fig. 10. Effect of $\mathrm{CO}_{2}$ stagnation condition on gain for fixed $\mathrm{N}_{2}$ stagnation; $\mathrm{T}_{\mathrm{N}}^{\mathrm{S}}=2000^{\circ} \mathrm{K}$, $p_{N}^{s}=5.7 \mathrm{~atm}, \mathrm{CO}_{2}: \mathrm{He}=2: 3, A_{C} / A_{C}^{*}=4$. 


\section{Acknowledgement}

The authors are grateful to express their thanks to Mr. K. Funabiki of ISAS, University of Tokyo for his helpful technical assistances.

\section{References}

1 N. G. Basov, A. N. Oraevskii, V. A. Schegiov, Soviet Phys., Tech. Phys., 15, 126 (1970).

2 J. P. E. Taran, M. Charpenel, R. Borghi, AIAA Paper, No. 73-622 (1973).

${ }^{3}$ V. N. Croshko, R. I. Soloukhin, N. A. Fomin, Combustion, Explosion, and Shock Waves, 10, 410 (1974).

4 V. N. Croshko, N. A. Fomin, R. I. Soloukhin, Acta Astronautica, 2, 929 (1975).

5 W. Scha11, P. Hoffmann, H. Hügel, J. Appl, Phys., $\underline{48}, 688(1977)$.

6 P. E. Cassady, J. Newton, P. Rose, AIAA J. 16, $305(1976)$.

7 A. V. Kraukitis, V. N. Croshko, R. I. Soloukhin, N. A. Fomin, Combustion, Explosion, and Shock Waves, 12, 709 (1977).

${ }^{8}$ R. Bailly, M. Pealat, J. P. E. Taran, Revue de Physique Appliquee, 12, 1705 (7977).

9 R. I. Soloukhin, in Shock Tube and Shock Wave Research, Proc. 11th Intern. Symposium on Shock
Tubes and Waves (University of Washington Press, Seattle, 1978) p.629.

10 P. E. Cassady, A. L. Pindroh, J. F. Newton, AIAA J., 17, 845 (1979).

11 P. E. Cassady, in Gas-Flow and Chemical Lasers, Proc. 2nd Intern. Symposium on Gas-Flow and Chemical Lasers (Hemisphere Publishing Corporation, Belgium, 1979) p.95.

${ }^{12}$ H. Oguchi, K. Funabiki, S. Sato, in Modern Development in Shock Tube Research, Proc. 10th Intern. Shock Tube Symposium (Kyoto Univ., Kyoto, 1975) p.387.

13H. Oguchi, K. Funabiki, S. Sato, ISAS Research Note, ISAS RN 20, University of Tokyo (1976).

${ }^{14}$ D. A. Russell, S. E. Neice, P. H. Rose, AIAA J. 13, 593 (1975).

$15 \mathrm{~J}$. D. Anderson, Jr., in Gas-Flow and Chemical Lasers, Proc. 2nd Intern. Symposium on Gas-Flow and Chemical Lasers (Hemisphere Publishing Corporation, Belgium,1979) p.3. 